\title{
Early diagnosis of cysts, a better option for a more conservative surgical treatment
}

\author{
Aldo vangjeli*, Bledar Bruka, Gentian Sekniqi and Maringlen Beqiraj \\ O.M.F Clinic, Regional Hospital Vlore, Albania
}

\begin{abstract}
Odontogenic cysts comprise most of the cystic lesions of the maxillofacial region. In our daily practice it may be the most common pathology we face. In many cases, the diagnosis of these lesions occurs randomly during routine checks or as a result of secondary inflammation overlapping in these pathologies. Sometimes, when diagnosed late these lesions appear with enlarged proportions with a wide spread of tissue, even replacing bone tissue and exacerbating their prognosis, which however remains positive but with a tendency of recurrence especially when these pathologies are of a great magnitude.
\end{abstract}

\section{Purpose}

The aim of this paper is to look at the sum of the periodontium, its functions, the possibility of its substitution or not, and we won't only shed light on the etiologic factors of this pathology, but we will also present complications stemming from late diagnosis of these lesions.

Another problem worth of discussing in our study is the definition of the exact boundary between periapical lesion, cystic granuloma and radicular cyst, in order to be correct when defining them. For this problem we have used the imaging and diameter of the periapical lesion.

Using bone grafts, the application of the elements gained by the patient's own blood processing by gaining plasma with enriched elements or growth-centered factors remains undoubtedly one of the primary goals of this paper, and as such the clinical cases that we will present will reflect these applications.

The etiology of this pathology remains theoretically correct. Their description remains an obligation not only because it is an important part of the anamnesis, but in some clinical cases, although without obvious symptoms at certain times, it may be the cause of various infections that can be dangerous for the patient's life.

a) Traumatic Causes: As a consequence of trauma, disruption of the neurovascular bundle and of the pulmonary circulation occurs. In the long term, this adds to the small and persistent trauma, which for the moment causes chronic aseptic periodontitis that is later joined by bacterial flora. Traumatic periodontitis can appear as a complication of the therapeutic treatment of radical canals by canal expansion instruments, or the passage of gutta-percha cones or filling materials beyond the apex to the periodontal space.

b) Infectious causes: Although the periodontium does not communicate with the oral environment, bacterial flora can penetrate (for continuitatum) from neighboring tissues, however the periodontal space may communicate with the mouth environment via root canal or gingiva on the tooth in the cases with paradontopathy. c) Chemical causes: Medicines such as arsenic, used during various therapeutic stages may be a causing factor of periodontitis, especially in the cases where the patient does not appear within 48 hours, but the periodontitis caused by medications may also appear from silicate-based filling materials and when there is no good isolation of the pulp chamber. We can mention the use of the cement in the cases of deep caries. The ortho-phosphoric acid free through the dentinal channels gives pulp necrosis which, after the overlap of the bacterial flora over time, gives periodontitis.

d) Human Causes or Factors: Sometimes for a variety of reasons, ranging from social and economic ones, to the negligence of the patient, we don't pay dental care enough attention.

Accurate diagnosis also requires auxiliary examinations especially the radiological ones. Nowadays, as we're living in the digital era, intuition guides you infallibly to the panoramic graphs as a first step and allows you to go step step-by-step to the tomographic graphs. In this context we cannot leave without mentioning telemedicine, although I think that it is still in the first steps of implementation.

Based on imaging when the lesion was over $1 \mathrm{~cm}$ we thought of a radical cyst and under this limit we thought of cystic granuloma or periapical lesion. We think it has a relative value for the treatment of these lesions by conservative or surgical path. We are of the opinion that lesions below $1 \mathrm{~cm}$ when therapeutic treatment has failed several times should be re-treated with correct endodontic treatment of the canal and apical resection, while in lesions over $1 \mathrm{~cm}$ the teeth affected by the cyst should be endontotically treated and cystectomy should be performed.

The periodontium formation ends approximately one year after the formation of root apex. In patients with mixed dentition in addition to the milk absorption phenomenon, periodontal space is

${ }^{*}$ Correspondence to: Aldo vangjeli, O.M.F Clinic, Regional Hospital Vlore, Albania, E-mail: aldo.vangjeli@yahoo.it

Received: November 07, 2018; Accepted: November 19, 2018; Published: December 23, 2018 
reduced. Periodontium is replaced by granulates. Thus during these developments the periodontal has no stable structure and thickness. Its thickness ranges between $0.2-0.25 \mathrm{~mm}$. This thickness can change from a variety of reasons, from the tooth function, age or any pathological process. The periodontal is composed of collagen yarn, of elastic fiber, short hairline connective tissue, cellular elements and many blood vessels, lymph and nerves [1-6].

Periodontal blood supply is partially provided by the arterial branches before they are inserted into the root canals. With interstitial arteries they form anastomoses for the jaw. In addition, there are other anastomoses between arterioles or periodontal and gingival capillaries. Blood vessels provide, especially in the period of osteogenesis or osteolysis, the needs of mineralized tissue for bone cement. These blood vessels serve at the same time as dental shock absorbers during the pressure exerted on them in chewing. Lymphatic periosteus and soft tissue lymph vessels together with the lymphatic vessels of the outer and inner limbs of the jawbone end up in the regional lymph nodes, this explains their involvement in the inflammatory processes.

\section{Periodontia is rich in cellular elements that allow it to perform a number of important functions.}

a. Formation: This is accomplished mainly by cementoblasts and osteoblasts. This is important for the treatment of periodontitis.

b. Holder and support: This limits the tooth movements when it is not in use, causes its fibers to disappear and be replaced with conjunctival tissue.

c. Sensitive: This serves as a warning system in cases of overload or trauma.

d. Feeder: This is necessary for the bone of cement.

e. Adaptive: This in the case of functional stimulants helps in the formation of the new cement needed for biological regeneration in the case of periapical pathological processes.
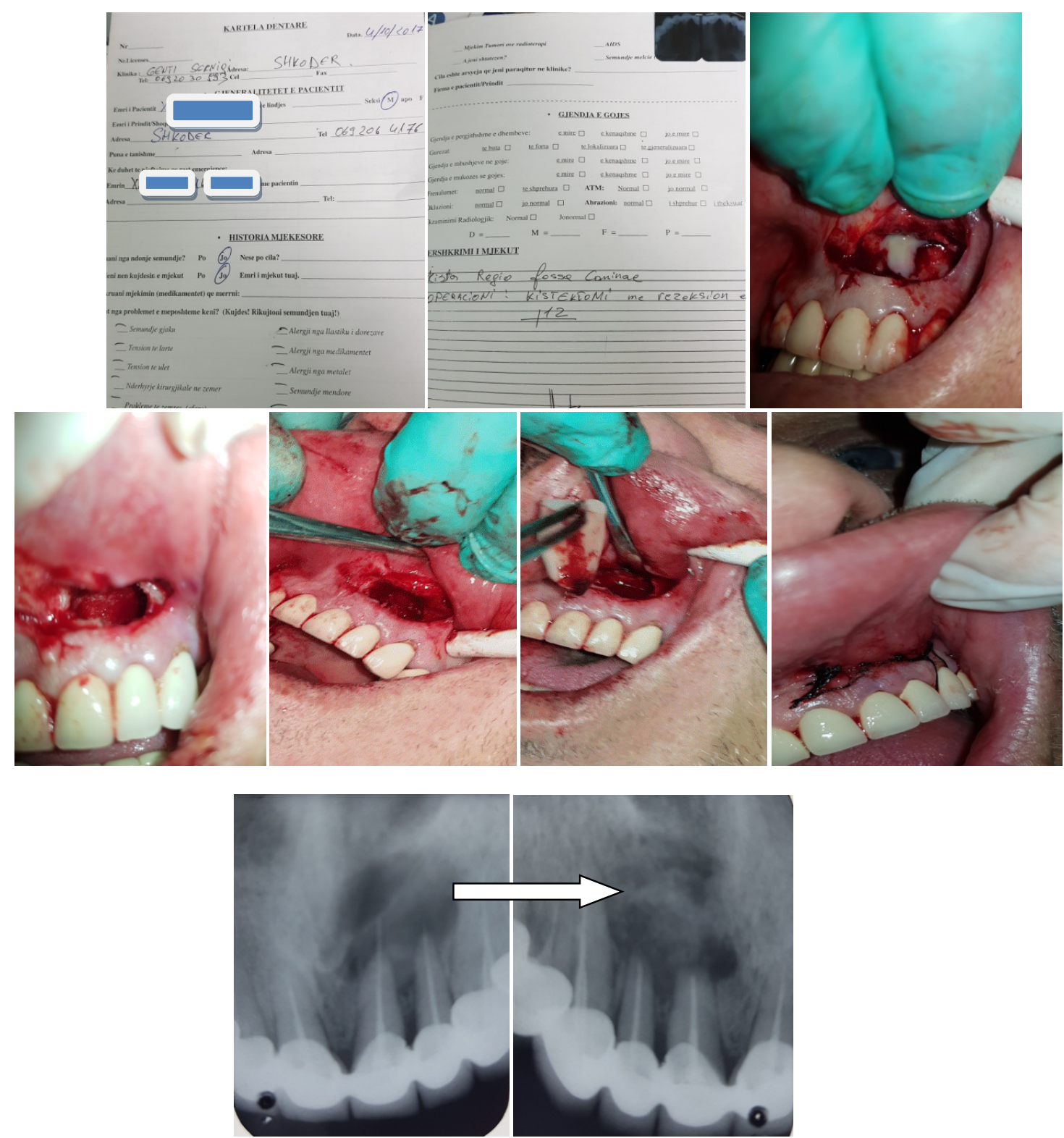

Figure 1. Cystectomy with 21.22 resection 
f. Fixing: This favors the physiological movement of the teeth as it not only connects the tooth with the alveolar but keeps it through the circular ligament.

g. Amortization: This is achieved by changing the volume of blood vessels and the combination of a large amount of fluid with colloidal cells.

From this point of view we should look at periodontium as closely related to the surrounding tissues, this is emphasized especially during the inflammatory processes when the initial changes affect one of the structures, which will also be reflected in the neighboring structures.

Material and Method: For this paper I have used my personal theoretical-practical experience in the surgical treatment of patients who have been exposed and have undergone surgical interventions during a time period of many years. In this paper I will present some clinical cases as below.

\section{Clinical cases}

Patient XH.L 45 years old is presented and diagnosed: 'Cysta regio fossa caninae'.

The recommended intervention is: 'Cystectomy with 21.22 resection' (Figure 1).

After radiological and laboratory auxiliary examinations, the patient undergoes surgery, where it was immediately discovered that the cystic pathology had overlapping secondary of purulent inflammation [7-9]. However, the cavity was carefully cleansed, sticky bone was prepared and the bloodstream membrane was placed in the cave cavity. (Figure 1)

The postoperative condition of the patient is good, after doing the control chart ambulatory treatment was recommended to the patient. The wound was cured 'Per primum'.
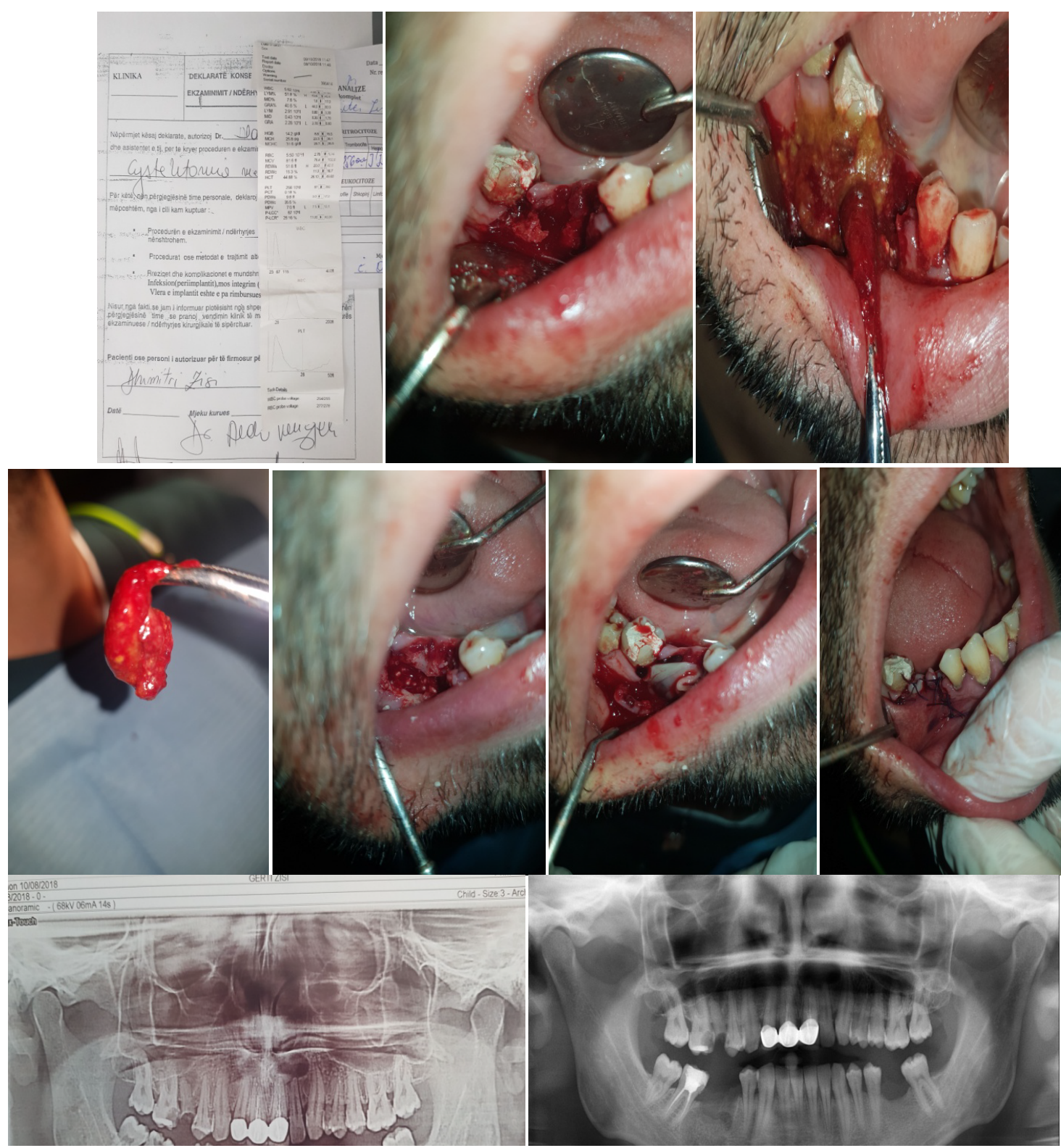

Figure 2. Cysta regio corpus mandibulae dextra 


\section{Case 2.}

The DH.Z. 32-year-old patient appears in the clinic with a perimandibular edema clinic. Panoramic graph confirms the diagnosis: 'Cysta regio corpus mandibulae dextra' (Figure 2).

The recommended intervention is: 'Cystectomy with radix extraction 45,46 '.

After radiological and laboratory auxiliary examinations, the patient underwent surgery.

Attempts were made and the intakes of the clay sacus were removed (Figure 2). The patient's postoperative posture status after doing the control chart was given ambulatory medication. The patient is under observation.

\section{Discussion}

Most of the cystic formations are discovered during radiological examinations. However, even during a clinical visit to cases of painlessness of the tonsils, there should be suspicion of a cystic pathology or not, and additional auxiliary examinations should be performed. Given reasonable doubts, it is necessary for the dentist to instruct patients to perform these radiological examinations not only to carry out the most accurate professional diagnosis but also to avoid the possible complications or consequences that stem from them.

\section{Conclusions}

1. The introduction of bone or synthetic bone grafts combined with the use of the membranes obtained by processing the patient's blood has brought a positive and incredibly useful innovation during the surgical treatment of the cysts with an absolute impact on their progress either in the postoperator stage and in the longterm pursuit.

2. Diagnosis and early treatment of periapical lesions based on contemporary protocols prevents the passage of massive cysts into the jaws, which causes major health problems to the patient.

3. The basic method for the treatment of radicular cysts is cystectomy and in some cases it is necessary to perform tooth preservation inside the cyst, this is especially neccessary when dealing with patients of young ages.

\section{References}

1. Doktoraturë Dr.Aldo Vangjeli me temë (2010) "Patologjitë periapikale dhe trajtimi terapeutik e kirurgjikal në këndvështrimin e kirurgut O.M.F."

2. Isufi R, Qendro A, Bardhoshi E (2010) Traktati i Kirurgjise Orale dhe Maksilofaciale.

3. Shtino G, Isufi R (2011) Atlasi i Kirurgjise Orale dhe Maksilofaciale Tiranë.

4. Goaz PW, White SC (1994) Oral radiology: principles and interpretation 3rd ed. St Louis, Mo: Mosby-Year Book 398-676.

5. Weber AL (1993) Imaging of cysts and odontogenic tumors of the jaw. Radiol Clin North Am 31: 101-120. [Crossref]

6. Oikarinen VJ (1990) Keratocyst recurrences at intervals of more than 10 years: case reports. Br J Oral Maxillofac Surg 28: 47-49. [Crossref]

7. Mourshed F (1967) A roentgenographic study of dentigerous cysts. Oral Surg Oral Med Oral Pathol 51: 54-61. [Crossref]

8. Regezi JA, Kerr DA, Courtney RM (1978) Odontogenic tumors: an analysis of 706 cases. J Oral Surg 36: 771-778. [Crossref]

9. Eisenberg E, Eisenbud L (1997) Benign fibro-osseous diseases: current concepts in historical perspective. Oral Maxillofac Surg Clin North Am 9: 551-561.

Copyright: (C2018 Vangjeli A. This is an open-access article distributed under the terms of the Creative Commons Attribution License, which permits unrestricted use, distribution, and reproduction in any medium, provided the original author and source are credited. 